\title{
A novel synthetic Asiatic acid derivative induces apoptosis and inhibits proliferation and mobility of gastric cancer cells by suppressing STAT3 signaling pathway
}

\author{
This article was published in the following Dove Press journal: \\ OncoTargets and Therapy \\ 20 December 2016 \\ Number of times this article has been viewed
}

\author{
Gang Wang' \\ Yue Jing ${ }^{2}$ \\ Lingsen $\mathrm{CaO}^{3}$ \\ Changchang Gong' \\ Zhunan Gong ${ }^{1,3}$ \\ Xiangrong $\mathrm{CaO}^{3}$ \\ 'Center for New Drug Research and \\ Development, College of Life Science, \\ Nanjing Normal University, ${ }^{2}$ Central \\ Laboratory of Stomatology, Nanjing \\ Stomatological Hospital, Medical \\ School of Nanjing University, Jiangsu \\ Key Laboratory for Molecular and \\ Medical Biotechnology, College of Life \\ Sciences, Nanjing Normal University, \\ Nanjing, People's Republic of China
}

Correspondence: Zhunan Gong; Xiangrong $\mathrm{CaO}$

College of Life Sciences, Nanjing Normal University, No I Wenyuan Road, Nanjing, Jiangsu 210023, People's Republic of China

Tel +86 258589 I736;

$+8613951635581$

Fax $+86258589 \quad 1736$

Email gongzhunan@njnu.edu.cn;

caoxiangrong@njnu.edu.cn

\begin{abstract}
Activation of the transcription factor, signal transducers and activators of transcription 3 (STAT3), has been linked to the proliferation and migration of a variety of human cancer cells. These actions occur via the upregulation or downregulation of cell survival and tumor suppressor genes, respectively. Importantly, agents that can suppress STAT3 activation have the potential for use in the prevention and treatment of various cancers. In this study, an Asiatic acid (AA) derivative, $N$-(2 $\alpha, 3 \beta, 23$-acetoxyurs-12-en-28-oyl)-L-proline methyl ester (AA-PMe), is reported to dose dependently suppress constitutive STAT3 activation in gastric cancer cells. This inhibition was mediated by blockade of Janus-activated kinase 2. Additionally, AA-PMe regulated the expression of STAT3-modulated gene products, including cyclin D1, Bax, Bcl-2, c-Myc, and matrix metalloproteinase (MMP)-2 and MMP-9. Finally, transfection with both a STAT3 mimic and an inhibitor reversed the AA-PMe-driven modulation of STAT3 downstream gene products. Overall, these results suggest that AA-PMe is a novel blocker of STAT3 activation and has the potential for the prevention and treatment of gastric cancer.

Keywords: gastric cancer, signal transducer and activator of transcription 3, Asiatic acid derivative, cell cycle, apoptosis, invasion
\end{abstract}

\section{Introduction}

Gastric cancer is one of the common cancers with a high mortality rate and limited treatment options. ${ }^{1}$ This is particularly true for populations residing in less developed countries. $^{2}$ To this end, systemic chemotherapy treatment has been the primary means of treatment but has led to consistently disappointing results with both low response rates and high toxicity. ${ }^{3}$ Hence, it is critical to develop new compounds and novel strategies of gastric cancer therapeutics.

The family of signal transducer and activator of transcription (STAT) proteins has manifested their significant functions in tumor cell survival, proliferation, ${ }^{3}$ invasion, and mobility. ${ }^{4}$ Among them, STAT3 has been observed to be constitutively active in various cancer cells, including blood cancer cells (multiple myeloma, leukemia, and lymphoma) and solid tumor cells (lung cancer, melanoma, and prostate cancer)., After activation, STAT3 undergoes tyrosine phosphorylation, dimerization, DNA binding, and then transcription activation. The interaction between Janus-activated kinases (JAKs) and STAT3 mediates the phosphorylation process. JAK1, JAK2, JAK3, and TYK2, a non-JAK tyrosine kinase, have all taken part in the activation 
of STAT3. ${ }^{7,8}$ Under normal physiological conditions, cells exhibit transient STAT3 phosphorylation, but STAT3 is constitutively activated in a great majority of tumor cells. This robust finding implicates aberrant STAT3 signaling in tumor formation. ${ }^{9-14}$ Contrastingly, inhibition of STAT3 may develop anticancer effects. ${ }^{15}$ The downstream targets of STAT3 include many gene products, such as vascular endothelial growth factor for angiogenesis; matrix metalloproteinase (MMP)-9 and MMP-2 for cell mobility; and cyclin D1, survivin, Mcl-1, c-Myc, and Bcl-2 required for cell survival and proliferation. ${ }^{16,17}$ As a consequence, agents that suppress activation of STAT3 have the capability of prevention and treatment of cancer. ${ }^{16,18}$

Natural dietary ingredients are potent resources of STAT3 inhibitors. Additionally, numerous studies suggest that vegetables and fruits can potentially prevent cancer. ${ }^{19}$ Pentacyclic triterpenes are active constituents in many medicinal herbs and have been used to treat a large range of indications. ${ }^{20}$ Asiatic acid (AA) is a pentacyclic triterpenoid which is isolated from Centella asiatica, a tropical medicinal plant, and displays cytotoxicity in a number of cancer cell lines, including human breast cancer, ${ }^{21}$ colon cancer, ${ }^{22}$ glioblastoma, ${ }^{23}$ hepatoma, ${ }^{24}$ and melanoma cells. ${ }^{25}$ Previous laboratory work focused on the semisynthesis of several derivatives of AA and found that one of them, $N$ - $(2 \alpha, 3 \beta, 23$-acetoxyurs-12-en28-oyl)-L-proline methyl ester (AA-PMe), had the strongest inhibitory activity using several cancer cell lines in vitro. ${ }^{26}$ Furthermore, the results also indicated that AA-PMe may block cell cycle progression, induce cell apoptosis, and inhibit the mobility of gastric cancer cells. Crucially, these effects were apparent with almost no toxicity to normal cells. Given the crucial roles of STAT3 in survival, proliferation of cancer cells, as well as angiogenesis, it was hypothesized that AA-PMe exerted its activities partly through regulation of the STAT3 activation pathway. To test this hypothesis, gastric cancer cell lines were utilized in conjunction with AA-PMe. The results indicated that AA-PMe suppressed constitutively active STAT3 by downregulating expression of gene products related to cell proliferation and angiogenesis. This inhibition ultimately led to cell survival suppression, apoptosis induction, as well as blockade of migration and invasion in gastric cancer cells.

\section{Materials and methods Materials and reagents}

AA was isolated and purified by gradient elution from silica gel column chromatography with petroleum ether-acetone system after extracting with ethanol from C. asiatica (L.) urban. The derivative AA-PMe was obtained through structural modification of AA performed in the laboratory. ${ }^{26}$ The structures of AA and AA-PMe are shown in Figure 1. Proline was purchased from Aladdin (Shanghai, China). Dulbecco's Modified Eagle's Medium (DMEM) and fetal bovine serum (FBS) were all purchased from Life Technologies (Carlsbad, CA, USA). Rabbit polyclonal primary antibodies to phosphoSTAT3(Tyr $\left.{ }^{705}\right)$, JAK2, phospho-JAK2, c-Myc, MMP-2, and MMP-9, and mouse monoclonal primary antibody against cyclin D1 were all obtained from Cell Signaling Technology (Danvers, MA, USA). Rabbit polyclonal antibodies against Bax and Bcl-2 and the anti-rabbit horseradish peroxidase (HRP) conjugate secondary antibody were obtained from Abcam (Cambridge, UK). The anti-mouse HRP conjugate secondary antibody was sourced from Boster (Wuhan, China). The specific JAK inhibitor, pyridine 6, was purchased from Santa Cruz Biotechnology (Dallas, TX, USA).

\section{Cell lines}

SGC7901 (metastatic carcinoma of lymph node) were obtained from the Cell Bank of Chinese Academy of Sciences (Shanghai, China) and were cultured in DMEM
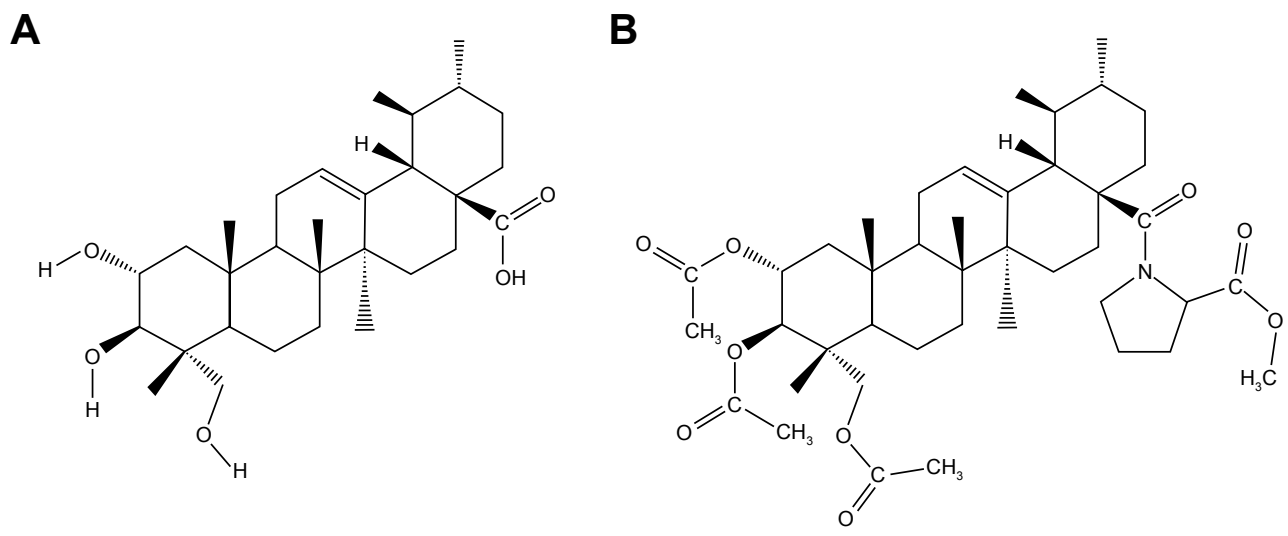

Figure I Chemical structure of AA (A) and AA-PMe (B).

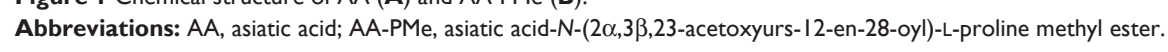


supplemented with $10 \%$ FBS (Life Technologies) in a $37^{\circ} \mathrm{C}$ humidified atmosphere containing $5 \% \mathrm{CO}_{2}$.

\section{Construction of recombinant eukaryotic expression vector}

A full-length, human STAT3 cDNA fragment was amplified using a forward primer (5'-TACAAGTACTCAGATC TCGAGATGGCCCAATGGAATCAGC-3') and a reverse primer (5'-CGACTGCAGAATTCGAAGCTTTCACAT GGGGGAGGTAG-3'), verified through sequencing, and double digested using XhoI-HindIII to get cohesive terminus. The resulting $2 \mathrm{~kb}$ fragment was purified using a gel/ polymerase chain reaction (PCR) extraction kit from Biomiga (San Diego, CA, USA) and was ligated to an XhoI-HindIIIdigested pEGFP-C3 vector DNA (BD Biosciences Clontech, Mountain View, CA, USA). Positive clones were further confirmed by XhoI-HindIII digestion and further sequencing. All vectors expressed green fluorescent protein as a reporter, thus enabling us to measure their infection efficiency.

\section{Construction of STAT3 shRNA- expressing vector}

Two complementary oligonucleotides for shSTAT3 (forward: 5'-GATCCGCAGCAGCTGAACAACATGTTCA AGAGACATGTTGTTCAGCTGCTGCTTTTTTGAAT TCA-3', reverse: 5'-AGCTTGAATTCAAAAAAGCAGC AGCTGAACAACATGTCTCTTGAACATGTTGTTCA GCTGCTGCG-3') were designed with BamHI and HindIII overhangs, which successfully interfered with the expression of human STAT3 mRNA. shRNA was obtained from Life Technologies. Double oligonucleotides were annealed by incubating in an annealing buffer for $10 \mathrm{~min}$ at $95^{\circ} \mathrm{C}$, followed by slow cooling to $37^{\circ} \mathrm{C}$. The annealed DNA was ligated with linearized pDC316-EGFP-U6 (Ambion, Austin, TX, USA) at the BamHI and HindIII sites. The plasmid DNA (pDC316-U6-STAT3) was isolated using a Biomiga Plasmid Miniprep Kit according to the manufacturer's instructions and verified by sequencing directly.

\section{STAT3 expressed and interfered plasmid transfection assay}

SGC7901 cells were seeded at densities of $5 \times 10^{4} / \mathrm{mL}$ on six-well plates and incubated overnight. They were then transiently transfected with either the pEGFP-C3-STAT3 or pDC316-EGFP-U6-STAT3 construct in serum-free DMEM or RPMI1640 using Lipofectamine 2000 reagent (Invitrogen, Waltham, MA, USA). After $6 \mathrm{~h}$ transfection, the medium was replaced with either DMEM or RPMI1640 media containing
$10 \%$ FBS. At $12 \mathrm{~h}$ post-transfection, cells were treated with AA-PMe at concentrations of $1,5,10,25$, and $50 \mu \mathrm{M}$ for $24 \mathrm{~h}$ and whole-cell extracts prepared with radioimmunoprecipitation assay (RIPA) lysis buffer were used to examine the levels of total STAT3 and phosphorylated STAT3 using Western blot.

\section{Western blot analysis}

After AA-PMe treatment, the whole-cell extracts were lysed in RIPA buffer $(0.01 \%$ phenylmethane sulfonyl flouride, $150 \mathrm{mmol} / \mathrm{L} \mathrm{NaCl}, 50 \mathrm{mmol} / \mathrm{L}$ Tris, $\mathrm{pH}=8,0.1 \%$ sodium dodecyl sulfate [SDS], $0.2 \%$ ethylenediaminetetraacetic acid, 1\% Triton X-100, 1\% sodium deoxycholate) supplemented with protease and phosphatase inhibitor cocktails (Roche, Basel, Switzerland). Lysates were incubated on ice for $30 \mathrm{~min}$ and centrifuged (model 5804R; Eppendorf, Hamburg, Germany) at 12,000 rpm for $15 \mathrm{~min}$. The protein concentrations were determined using a Bicinchoninic Acid Protein Assay Kit (Sigma-Aldrich, Milan, Italy). Wholecell extracts $(50 \mu \mathrm{g})$ were electrophoresed on $10 \%$ SDS gels and transferred to a polyvinylidene fluoride membrane (Millipore, Billerica, MA, USA). After electrotransfer, the proteins were blocked in Tris-buffered saline containing $0.05 \%$ Tween 20 supplemented with $5 \%$ nonfat dry milk for $1 \mathrm{~h}$ at room temperature, and probed with primary antibodies at $4^{\circ} \mathrm{C}$ overnight, followed by incubation with secondary antibody for $1 \mathrm{~h}$ at room temperature. Resulting protein bands were visualized using FluorChem E (ProteinSimple, Santa Clara, CA, USA).

\section{Real-time reverse transcription PCR}

Total mRNA was extracted using Trizol reagent (Invitrogen) and quantified using a spectrophotometer (NanoDrop ND-1000, USA). Reverse transcription was carried out to synthesize cDNA using a cDNA synthesis kit (Vazyme, Nanjing, China). Real-time quantitative PCR for stat 3 was detected by a Step One Plus Real-time PCR system (ABI, Oyster Bay, NY, USA) with SYBR Green Master Mix (Roche). Primers were designed and synthesized by Sangon Biotech Co. Ltd (Shanghai, China). All primer sequences used in reverse transcription PCR are listed in Table 1.

Table I Primer sequences for RT-PCR

\begin{tabular}{lll}
\hline Gene & \multicolumn{2}{l}{ Primer sequence } \\
\hline GAPDH & Forward & 5'-TGGTGAAGACGCCAGTGGA-3' \\
& Reverse & 5'-GCACCGTCAAGGCTGAGAAC-3' \\
stat3 & Forward & 5'-CTGGCCTTTGGTGTTGAAAT-3' \\
& Reverse & 5'-AGGGCGAGGACCATAGAGG-3' \\
\hline
\end{tabular}

Abbreviation: RT-PCR, reverse transcription polymerase chain reaction. 
Targeted mRNA expression was quantified in comparison with human GAPDH mRNA. Experiments were performed in triplicate, and the data were calculated by $\Delta \Delta \mathrm{Ct}$ methods.

\section{Annexin V-fluorescein isothiocyanate (FITC)/propidium iodide (PI) assay}

In early apoptosis, translocation of phospholipid phosphatidylserine from the cytoplasmic interface to the cell surface leads to loss of membrane asymmetry, which can be detected by Annexin V. ${ }^{27,28}$ To explore the effects of AA-PMe on cell apoptosis, SGC7901 cells were first transfected with either recombinant STAT3 plasmid or shRNA, and then incubated with AA-PMe for $24 \mathrm{~h}$ at concentrations of 5,10 , or $50 \mu \mathrm{M}$. Cells were then collected, washed with phosphate-buffered saline (PBS), stained by Annexin V-FITC and PI, and analyzed using a flow cytometer (BD Biosciences).

\section{Cell cycle assay}

To test the effect of AA-PMe on cell cycle, SGC7901 cells were first transfected with either recombinant STAT3 plasmid or shRNA and then incubated with AA-PMe at different concentrations for $24 \mathrm{~h}$. Cells were then washed in PBS, fixed on $75 \%$ ethanol, and incubated with $20 \mu \mathrm{L}$ RNase A solution for $30 \mathrm{~min}$ at $37^{\circ} \mathrm{C}$. They were stained by $400 \mu \mathrm{L}$ PI solution for $30 \mathrm{~min}$ at $4^{\circ} \mathrm{C}$ and cell cycle was analyzed using a FACSCalibur flow cytometer at $488 \mathrm{~nm}$.

\section{Trypan blue staining assay}

Cells were added to six-well plate, transfected with plasmid, and exposed to AA-PMe at concentrations of $0,5,10$, or $50 \mu \mathrm{M}$. They were then harvested and dyed with trypan blue to label all dead cells.

\section{Cell invasion assay}

Transwell chambers (Corning, NY, USA) were precoated with Matrigel (BD Biosciences) and used for cell invasion assays. Briefly, the transwell chambers were placed on a 24-well plate, and $600 \mu \mathrm{L}$ culture medium with either AA or AA-PMe (supplemented with 10\% FBS) was added to the lower chamber as a chemo-attractant. Cancer cells $\left(1 \times 10^{5} / \mathrm{mL}\right)$ suspended in $200 \mu \mathrm{L} 1 \%$ FBS culture medium were then added to the upper chamber. After $24 \mathrm{~h}$ incubation, the noninvasive cells were removed using cotton swabs. The cells that traversed the membrane pore and spread to the lower surface of the filters were fixed and stained by $0.1 \%$ crystal violet for subsequent visualization. Images were filmed with a Cannon Power Shot A640 camera under a Zeiss inverted microscope ( $\times 100$ magnification). Subsequently,
$33 \%$ acetic acid was applied for $10 \mathrm{~min}$ to decolor invasive cells and the absorbance of the solution was measured by a microplate reader at $570 \mathrm{~nm}$ (Thermo Fisher Scientific, Waltham, MA, USA). Cell invasive viability was expressed by the invasive cell number, and inhibition percentage of invasion according to the following formula as well:

$$
\begin{gathered}
\text { Inhibition percentage } \\
\text { of invasion }(\%)
\end{gathered}=\frac{\text { ODtreated }- \text { ODblank }}{\text { ODcontrol - ODblank }} \times 100 \%
$$

\section{Statistical analysis}

All data were expressed as mean \pm standard deviation. Comparisons among multiple groups were made using a one-way analysis of variance followed by Dunnett's test. $P<0.05$ was used as the threshold for statistical significance.

\section{Results}

STAT3 plays a crucial role in the survival, proliferation, and mobility of cancer cells. In the present study, the effect of an AA derivative - AA-PMe - on signaling pathway of both constitutively active and JAK2 inhibited STAT3 in two gastric cancer cell lines. The effect of AA-PMe was also observed on a variety of STAT3 downstream mediators of cell survival, proliferation, apoptosis, and invasion.

\section{AA-PMe inhibited phosphorylation of constitutively active STAT3 in human gastric cancer cells}

This study first sought to determine whether incubating human gastric cancer cells with AA-PMe would 1) modulate constitutive STAT3 activation and/or 2) show a stronger inhibition of pSTAT3 than AA. SGC7901 cells were treated with either AA or AA-PMe at a series of concentrations for $24 \mathrm{~h}$. Whole-cell extracts were examined by Western blot for levels of phosphorylated STAT3 using an antibody to recognize phosphorylation of STAT3 at $\mathrm{Tyr}^{705}$. As shown in Figure 2, both AA and AA-PMe inhibited constitutive activation of STAT3 in SGC7901 cells in a concentrationdependent manner. However, AA-PMe had maximum inhibition from 10 to $50 \mu \mathrm{M}$. Comparatively, incubation with AA yielded maximum inhibition at a higher range of 25-50 $\mu \mathrm{M}$, illustrating that AA-PMe exerts better suppression of pSTAT3 expression than AA. Neither AA nor AAPMe had an effect on the levels of total STAT3 (Figure 2A). The density of each band was measured and normalized to that of GAPDH (Figure 2B). Interestingly, the stat3 realtime PCR analysis showed that the expression of stat 3 was 
A

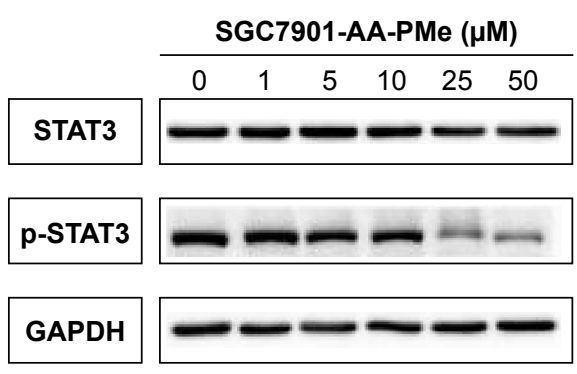

B

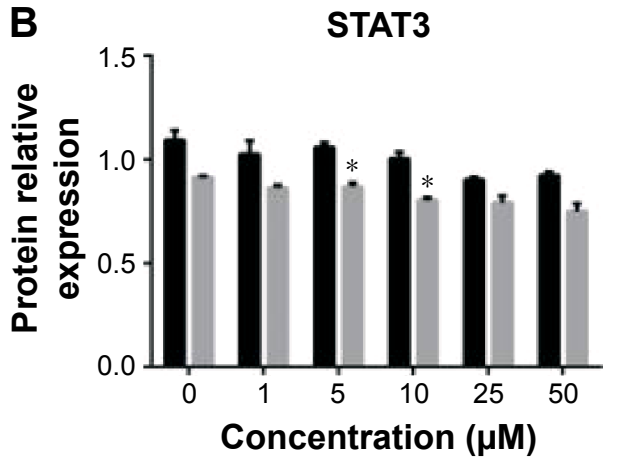

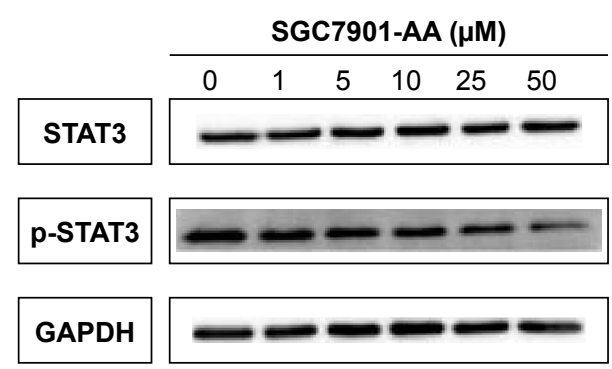

pSTAT3

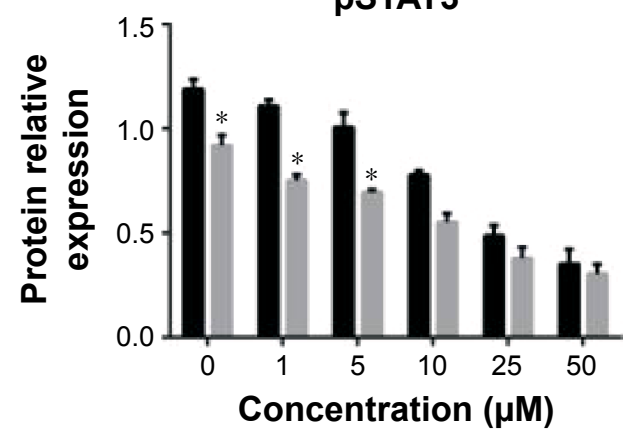

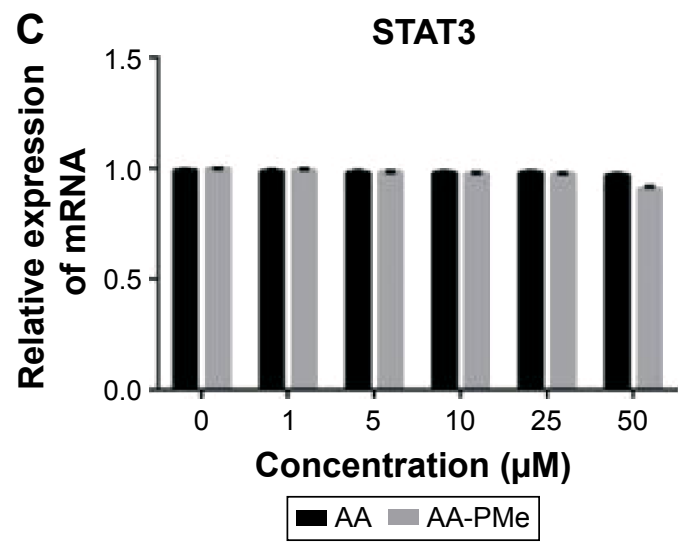

Figure 2 Comparison of STAT3 expression and activation in AA-PMe- and AA-treated SGC790I cells.

Notes: (A) Western blot analysis of total STAT3, phosphorylation of STAT3 in AA-PMe- and AA-treated SGC790I cells. (B) Histogram presenting the relative expression levels of STAT3 and PSTAT3 protein after normalization to their corresponding internal controls. (C) Expression of stat3 mRNA levels using RT-PCR. Significant differences are denoted by $* P<0.05$.

Abbreviations: AA, asiatic acid; AA-PMe, $\mathrm{N}-(2 \alpha, 3 \beta, 23$-acetoxyurs-12-en-28-oyl)-L-proline methyl ester; STAT3, signal transducers and activators of transcription 3; RT-PCR, reverse transcription polymerase chain reaction.

significantly decreased in AA-PMe-treated cells relative to AA-treated cells (Figure 2C).

\section{AA-PMe inhibited STAT3 phosphorylation by regulating JAK2 in human gastric cancer cells}

Next, the effects of AA-PMe on the activation of STAT3 in the case of JAK2 blockade were investigated. Cancer cells were incubated with pyridine $6(1 \mu \mathrm{M})$, a specific inhibitor of JAK2 for $12 \mathrm{~h}$, and then treated with different concentrations of AA-PMe, and the protein expression was subsequently analyzed. As shown in Figure 3A, inhibition of JAK2 significantly downregulated the expression of both
pJAK2 and pSTAT3, suggesting that AA-PMe might have inhibited the activation of JAK2 and STAT3 by blocking JAK2 in SGC7901 cells.

\section{AA-PMe-induced inhibition of STAT3 phosphorylation is reversible in human gastric cancer cells}

The study next examined whether AA-induced inhibition of STAT3 phosphorylation is reversible. SGC7901 cells were treated with AA-PMe for $60 \mathrm{~min}$, washed with PBS to remove any remaining then cultured in fresh medium for different durations, and the levels of pSTAT3 were measured. Results indicated that AA-PMe suppressed STAT3 phosphorylation after 
A
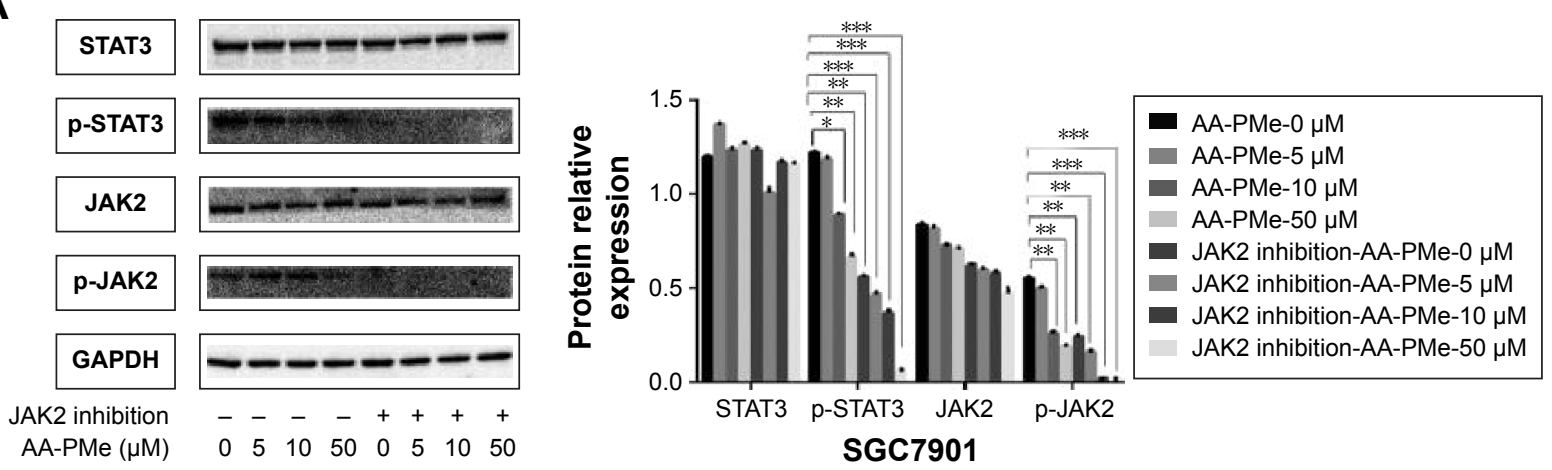

B
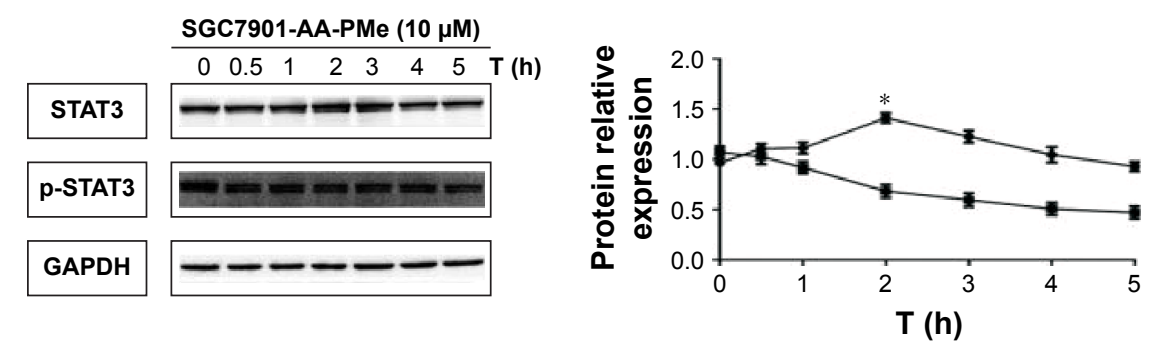

C
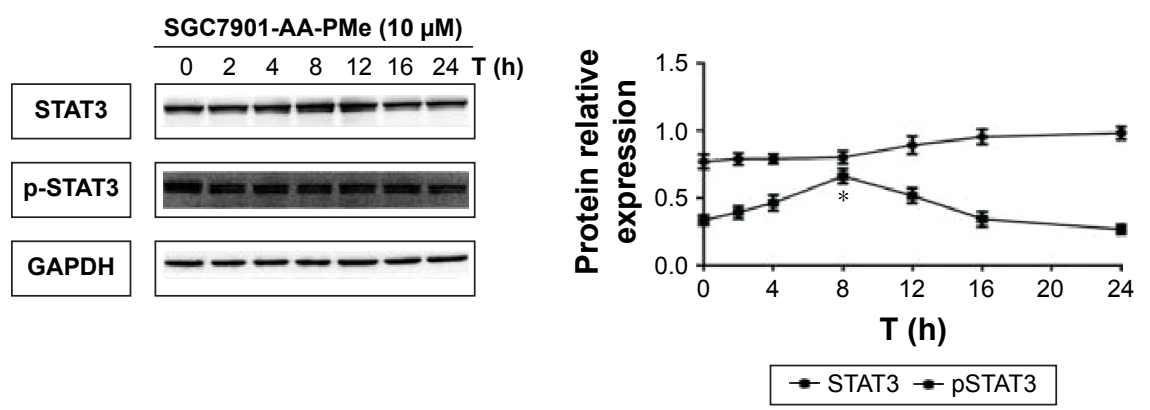

Figure 3 AA-PMe regulated JAK2-STAT3 pathway in gastric cancer cells.

Notes: (A) Gastric cancer cells were treated with a JAK2 inhibitor, lysed, and subjected to immunoblotting. SGC790I cells $\left(2 \times 10^{6} / \mathrm{mL}\right)$ were treated with $10 \mu M$ AA-PMe for the indicated duration (B) or for I $\mathrm{h}$ and washed with PBS twice to remove AA-PMe before resuspension in fresh medium. Cells were removed at the indicated time points and lysed to prepare the whole-cell extract. (C) Whole-cell extracts $(50 \mu \mathrm{g})$ were resolved on $10 \%$ SDS-PAGE, transferred to a nitrocellulose membrane, probed for phosphorylated STAT3, and stripped and reprobed with STAT3 antibodies. Histogram presented the relative expression levels of STAT3 and PSTAT3. Representative of three independent experiments. Significant differences are denoted by $* P<0.05, * * P<0.0$ I, and $* * * P<0.00$ I.

Abbreviations: AA-PMe, asiatic acid-N-(2 $\alpha, 3 \beta, 23$-acetoxyurs-12-en-28-oyl)-L-proline methyl ester; STAT3, signal transducers and activators of transcription 3; JAK2, Janus-activated kinase 2; SDS, sodium dodecyl sulfate; PAGE, polyacrylamide gel electrophoresis.

$2 \mathrm{~h}$ of incubation (Figure 3B). Furthermore, the removal of AAPMe resulted in a gradual increase of phosphorylated STAT3 (Figure 3C). The reversal in pSTAT3 levels was completed by $12 \mathrm{~h}$ before gradually increasing until $24 \mathrm{~h}$ post-incubation. Alterations in the pSTAT3 levels were not paralleled by any changes in STAT3 protein levels (Figure 3B and C).

\section{Knockdown and overexpression of stat3 changed the expression of downstream targets induced by AA-PMe}

It has been shown that STAT3 activation regulates the expression of a variety of gene products involved in cell survival, proliferation, and mobility, for example, the cell cycle regulatory protein cyclin $\mathrm{D} 1$, the proapoptotic protein Bax, the antiapoptotic protein Bcl-2, and MMP-2 and MMP-9. ${ }^{16,18,29,30}$
In previous studies, it has been found that expression of cyclin D1, Bcl-2, Bax, MMP-2, and MMP-9 were all regulated by AA-PMe. ${ }^{31}$ Thus, whether AA-PMe might regulate these proteins via STAT3 was investigated. To better understand the effects of AA-PMe on STAT3 in gastric cancer cells, SGC7901 cells were transfected with either a stat 3 overexpressed or interfered plasmid. Western blot analysis showed that the levels of both STAT3 and pSTAT3 were significantly increased in cells transfected with the stat 3 overexpressed plasmid, while levels were significantly decreased with the stat 3 interfered plasmid.

Simultaneously, it was also found that compared to the un-transfected group, AA-PMe-induced expression changes in cyclin D1, Bax, Bcl-2, c-Myc, MMP-9, and MMP-2 were effectively reversed upon transfection with stat 3 shRNA and the overexpressed plasmid (Figure 4). 
A

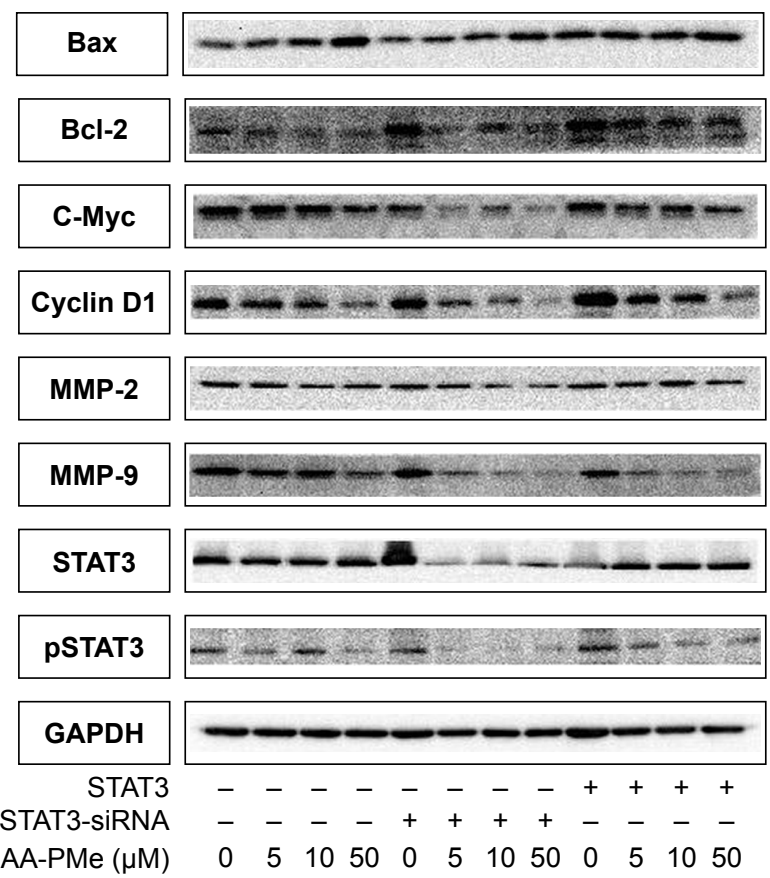

B
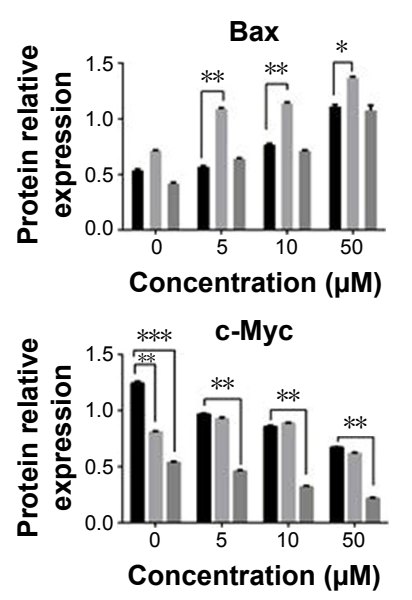

MMP-2

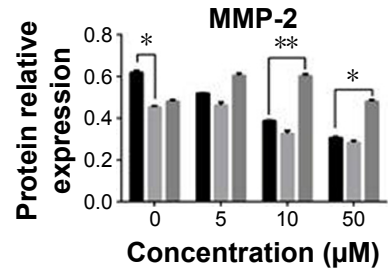

STAT3

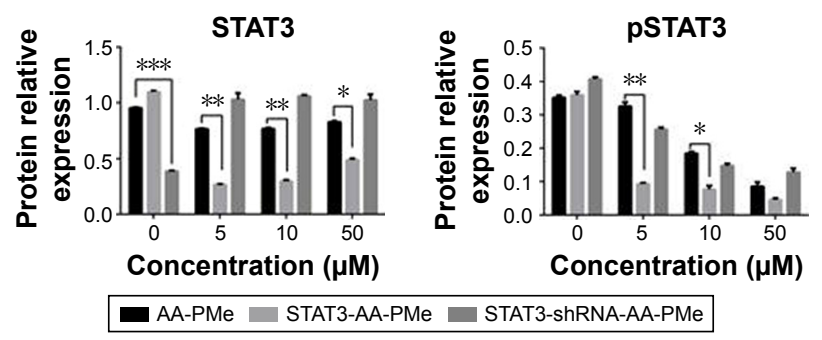

$\mathrm{Bcl}-2$
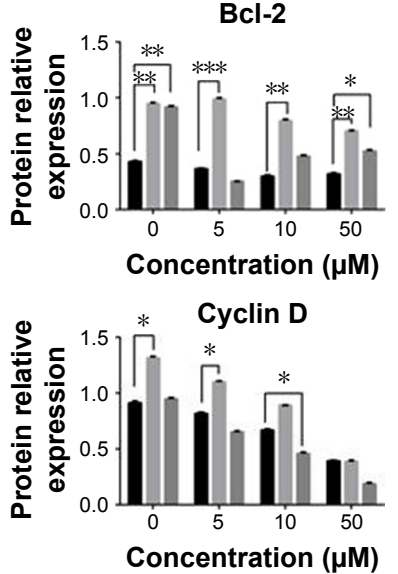

MMP-9

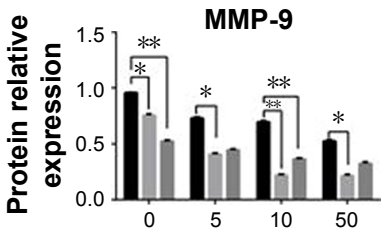

Concentration $(\mu \mathrm{M})$

pSTAT3

Figure 4 Transfection with STAT3 shRNA and STAT3 expression plasmid in SGC790I modulated the expression of proteins, which were induced by AA-PMe. Notes: SGC790I cells $\left(2 \times 10^{6} / \mathrm{mL}\right)$ were transfected with either shSTAT3 or STAT3 plasmid. After $24 \mathrm{~h}$, cells were treated with 5 , I0, and $50 \mu M$ AA-PMe for another $24 \mathrm{~h}$ and the whole-cell extracts were subjected to Western blot analysis for STAT3, pSTAT3, Bax, Bcl-2, c-Myc, cyclin DI, and MMP-2, and MMP-9 (A). The density of A was analyzed according to GAPDH (B). Representative of three independent experiments. Significant differences are denoted by $* P<0.05$, $* * P<0.0 \mathrm{I}$, and $* * * P<0.00 \mathrm{I}$.

Abbreviations: AA-PMe, asiatic acid-N-(2 $\alpha, 3 \beta, 23$-acetoxyurs-12-en-28-oyl)-L-proline methyl ester; STAT3, signal transducers and activators of transcription 3; MMP, matrix metalloproteinase.

\section{JAK2-STAT3 pathway regulated AA-PMe- induced cellular viability}

To better understand the role of stat 3 in cell survival of SGC7901 cells treated by AA-PMe, the effects of both stat 3 overexpression and knockdown were tested. Using a trypan blue assay, it was found that cells transfected with stat 3 shRNA had a significantly higher survival ratio. Those transfected with the stat 3 mimic had a significantly lower survival ratio when compared to the un-transfected group, AA-PMe-treated cells (Figure 5). These results suggest that STAT3 contributes to the survival of gastric cancer cells treated with AA-PMe.

\section{JAK2-STAT3 pathway regulated AA-PMe- induced cell cycle arrest}

Results showed that incubation with AA-PMe dose dependently arrested cell cycle at G0/G1 phase. Without AA-PMe

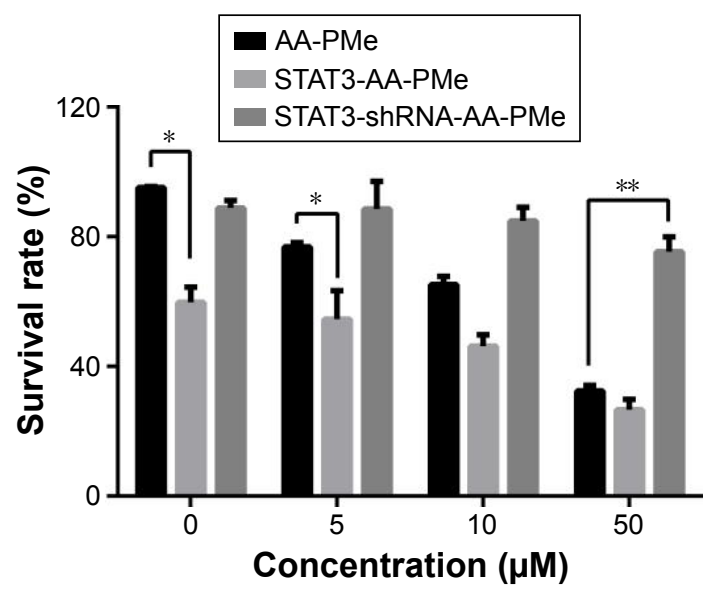

Figure 5 AA-PMe modulated proliferation by inhibiting STAT3 in gastric cancer cells.

Notes: STAT3 confers AA-PMe inhibition in SGC790I cells. SGC790I cells $48 \mathrm{~h}$ after transfection with stat 3 mimic and inhibitor were subsequently treated with various doses of AA-PMe $(5,10$, and $50 \mu \mathrm{M})$ for $24 \mathrm{~h}$. Cell viability was determined using a trypan blue assay. Significant differences are denoted by $* P<0.05, * * P<0.01$.

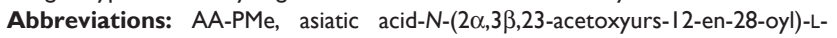
proline methyl ester; STAT3, signal transducers and activators of transcription 3. 
treatment, the cells in the G0/G1 phase decreased from $51.31 \%$ to $41.25 \%$ after being transfected with STAT3 shRNA. However, upon transfection with the STAT3 overexpressed plasmid, the cells in the G0/G1 phase increased from $51.31 \%$ to $55.84 \%$ (Figure 6). These results indicate that STAT3 plays crucial roles in the cell cycle arrest induced by treatment with AA-PMe.

\section{JAK2-STAT3 pathway regulated AA-PMe- induced cellular apoptosis}

To investigate whether STAT3 signaling has an influence on AA-PMe-induced apoptosis, Annexin V-FITC/PI staining assays were performed in drug-treated cells. The ratio of AA-PMe-induced apoptosis decreased markedly after transfection with STAT3 shRNA in SGC7901 cells, while the ratio increased upon transfection with the STAT3 mimic (Figure 7A and B). These data suggest that either inhibition or overexpression of STAT3 signaling can impact AA-PMeinduced apoptosis in gastric cancer cells.

\section{JAK2-STAT3 pathway regulated AA-PMe- induced cellular invasion}

A transwell study was then carried out to verify the function of STAT3 in AA-PMe-mediated SGC7901 invasion. In the invasion assay, it was found that STAT3 stimulation could significantly promote the invasion of SGC7901. However, comparing both STAT3 and the control group, STAT3 shRNA group exhibited lower motility as quantified by

\section{AA-PMe $(\mu \mathrm{M})$}

0

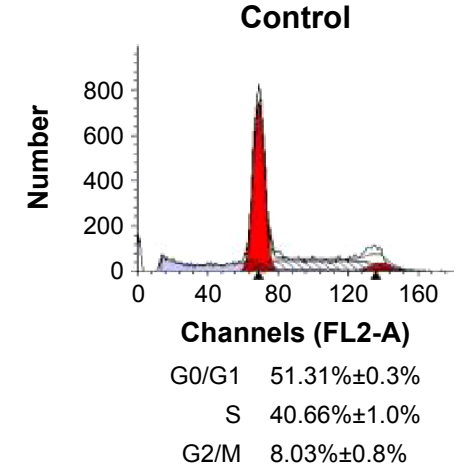

5

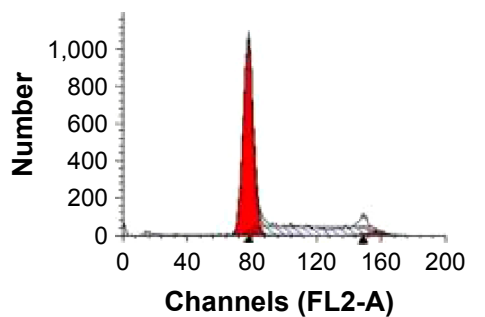

G0/G1 $66.74 \% \pm 2.3 \%$

S $\quad 31.23 \% \pm 1.4 \%$

G2/M $2.04 \% \pm 0.6 \%$

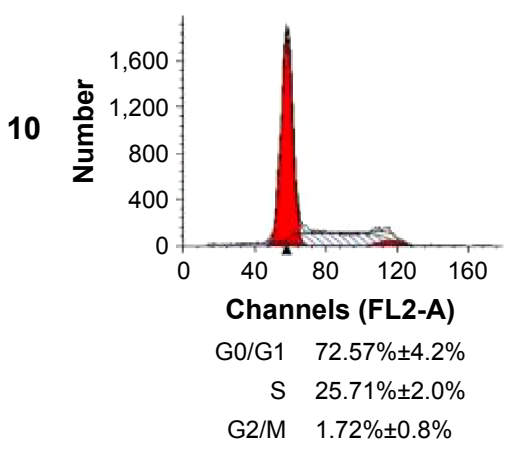

STAT3
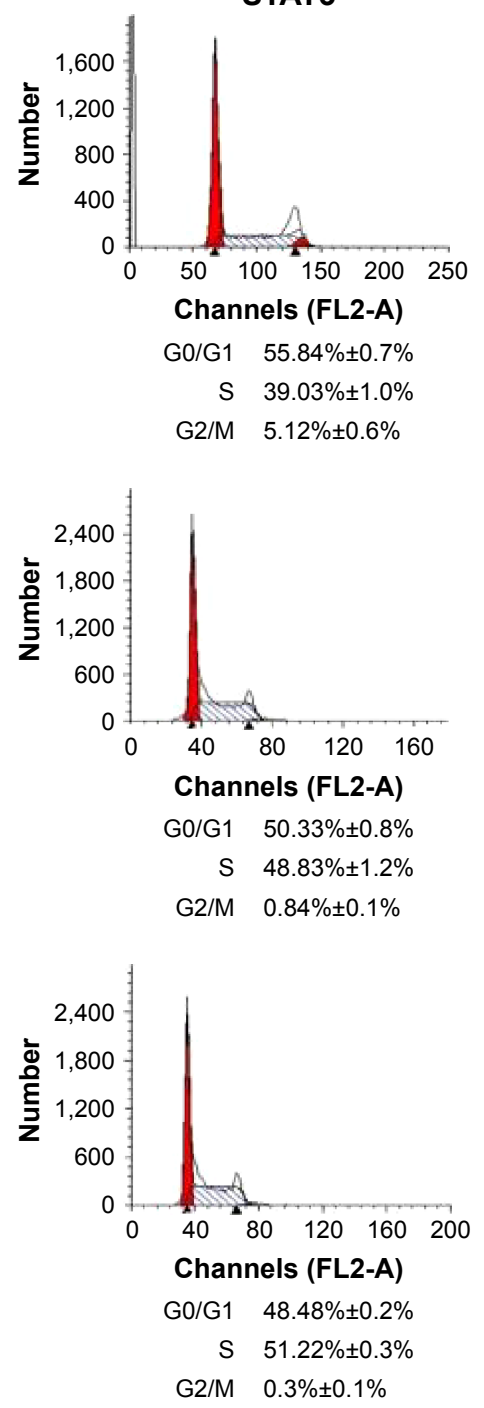

STAT3-shRNA
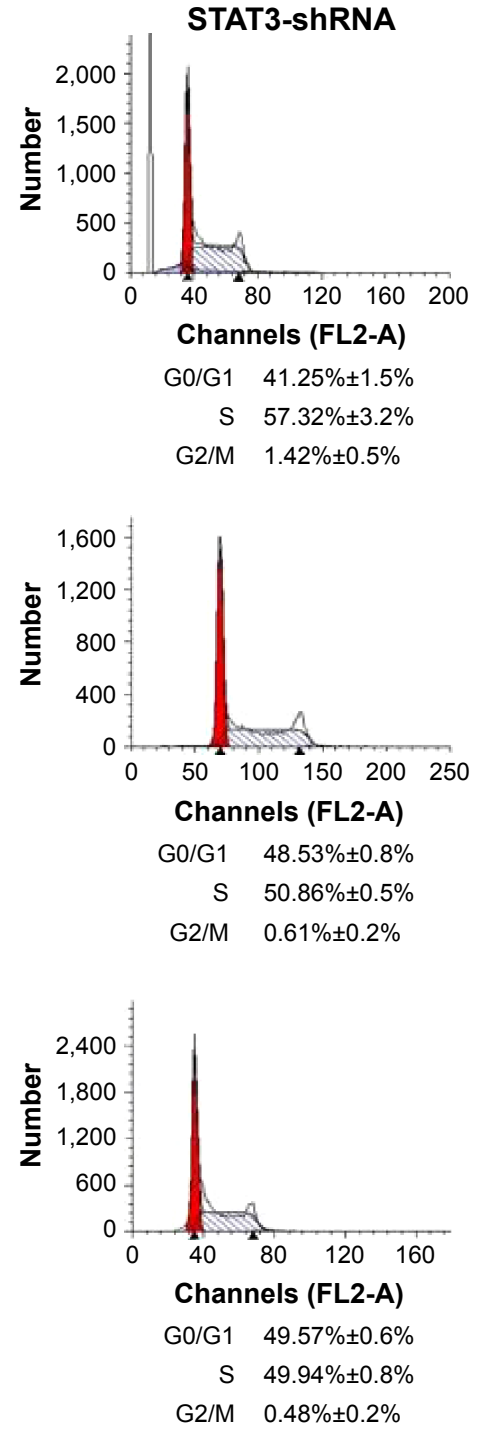

Figure 6 AA-PMe modulated cell cycle by inhibiting STAT3 in gastric cancer cells.

Notes: Transfection with STAT3 shRNA and STAT3 expression plasmid in SGC790I adjusted the G0/GI cell cycle arrest induced by AA-PMe. Cell cycles were analyzed by flow cytometry.

Abbreviations: AA-PMe, asiatic acid-N-(2 $\alpha, 3 \beta, 23$-acetoxyurs- I2-en-28-oyl)-L-proline methyl ester; STAT3, signal transducers and activators of transcription 3. 


\section{A $\mathrm{AA}-\mathrm{PMe}(\mu \mathrm{M}) \quad 0$}
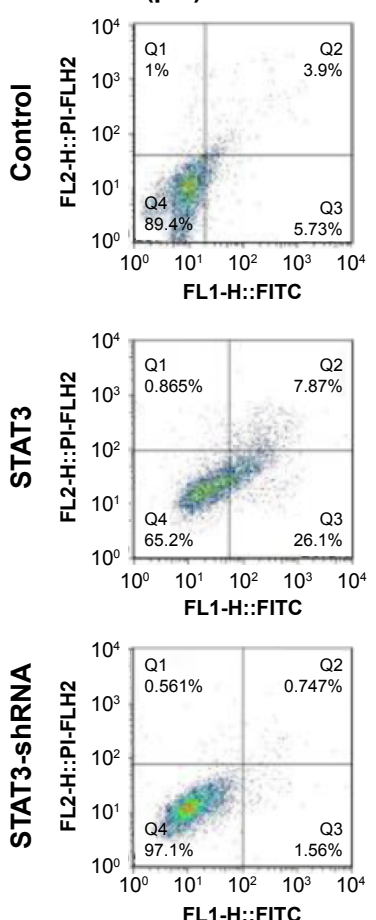
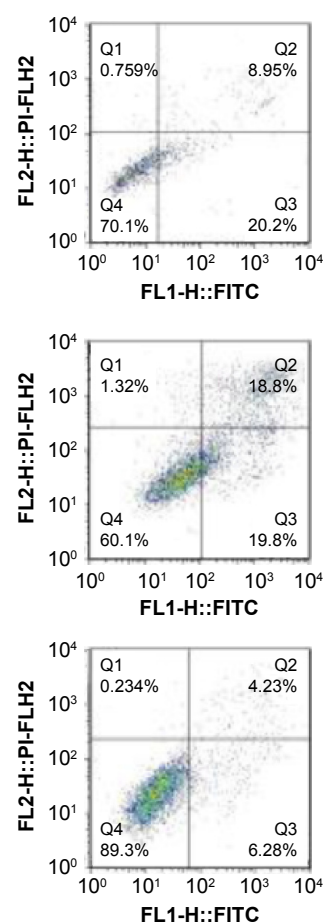

10
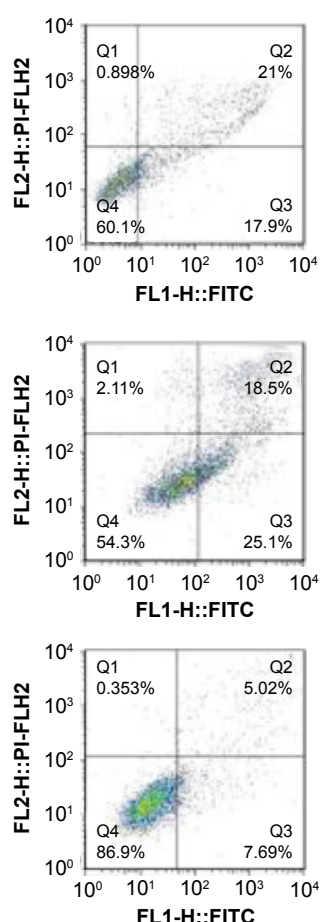

50
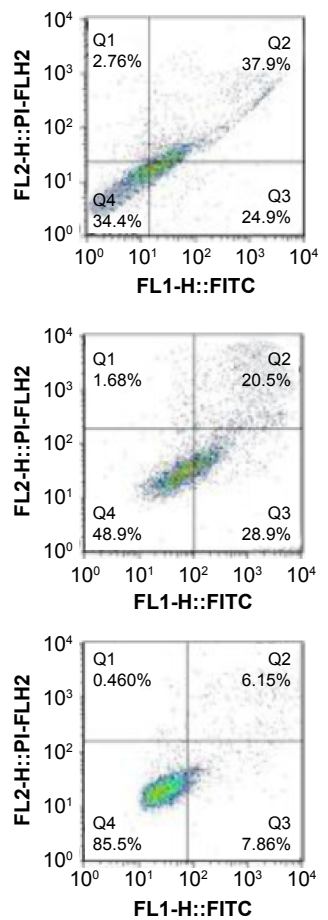

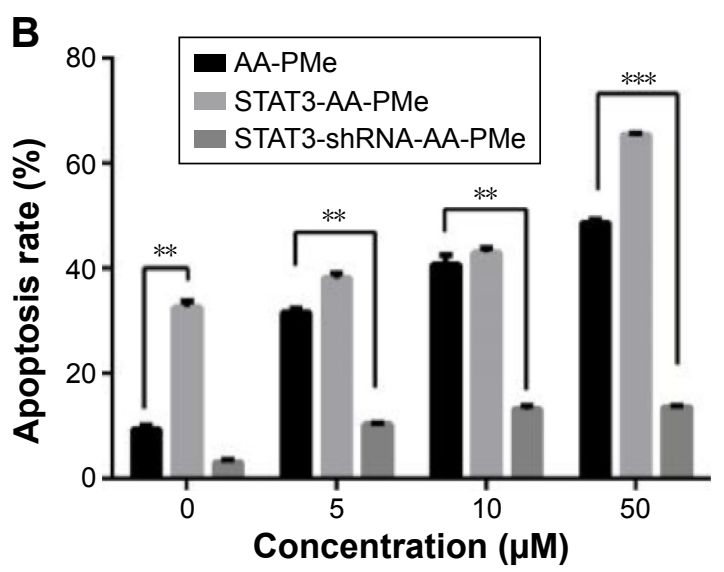

Figure 7 AA-PMe modulated apoptosis by inhibiting STAT3 in gastric cancer cells.

Notes: (A) Overexpression of stat3 induces SGC790I cells to tend to AA-PMe-induced apoptosis after $24 \mathrm{~h}$ in a dose-dependent manner, while knockdown stat3 induces SGC790I cells to become resistant to AA-PMe-induced apoptosis after $24 \mathrm{~h}$ in a dose-dependent manner. Cells were incubated with Annexin $\mathrm{V}$ and $\mathrm{PI}$ and then analyzed with a flow cytometer. (B) Apoptosis rate of Annexin V-FITC/PI assay. Significant differences are denoted by $* * P<0.001$ and $* * * P<0.001$.

Abbreviations: AA-PMe, asiatic acid-N-(2 $\alpha, 3 \beta, 23$-acetoxyurs-12-en-28-oyl)-L-proline methyl ester; STAT3, signal transducers and activators of transcription 3; FITC, fluorescein isothiocyanate; $\mathrm{PI}$, propidium iodide.

both invasive cells amounts and inhibitive invasion rate, and also had a suppressive effect on the invasive ability of cells (Figure 8A-C). Collectively, these data suggest that STAT3 plays a vital role in AA-PMe-induced invasion and mobility of gastric cancer cells.

\section{Discussion}

It has been previously shown that AA-PMe decreases the expression of a series of STAT3-regulated gene products, including the proliferative (cyclin D1), antiapoptotic (Bcl-2), proapoptotic (Bax), and tumor invasive (MMP-2 and MMP-9) factors. Constitutively active STAT3 plays critical roles in the induction of resistance to apoptosis, ${ }^{9}$ probably by increasing the expression of cyclin D1 and Bcl-2. ${ }^{32,33}$ AA-PMe-induced suppression of cell proliferation and cell cycle arrest at the G0/G1 phase were closely associated with the downregulation of cyclin D1 expression, which was consistent with the requirement of cyclin D1 for cell cycle transition from G1 to $\mathrm{S}$ phase. AA-PMe-induced apoptosis of gastric cancer cells was likely to link with downregulation of Bcl-2 and 
A AA-PMe

$(\mu \mathrm{M})$
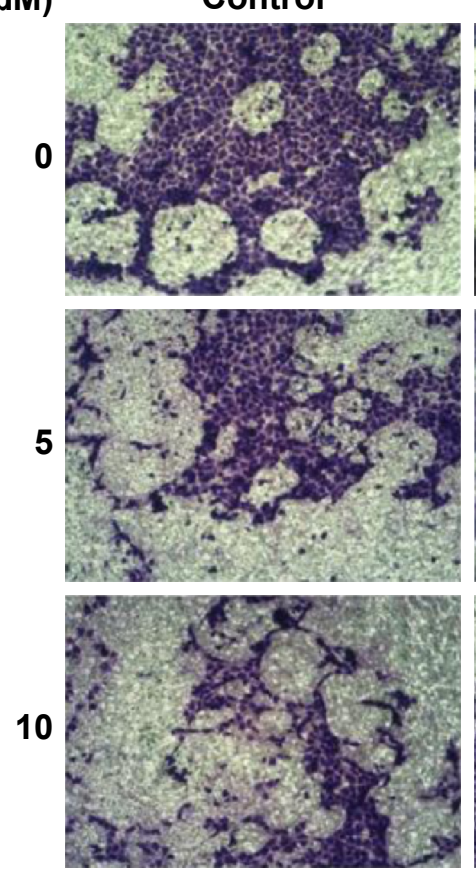

STAT3
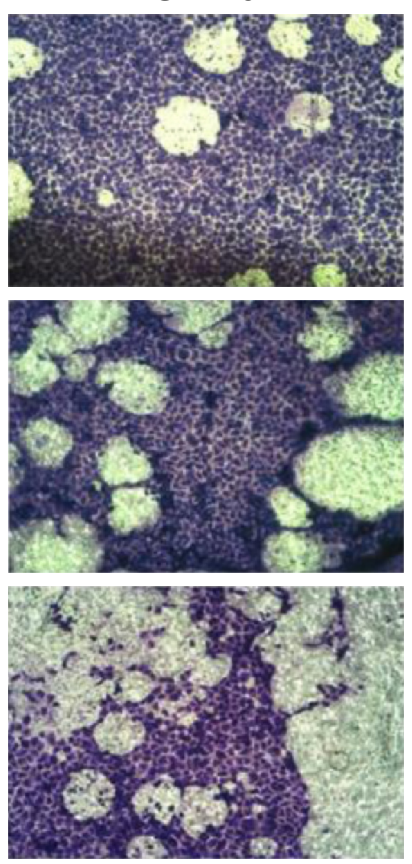

STAT3-ShRNA
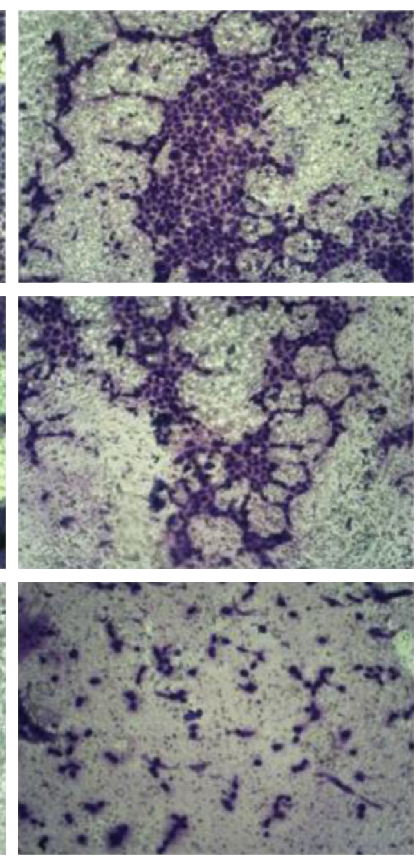

B

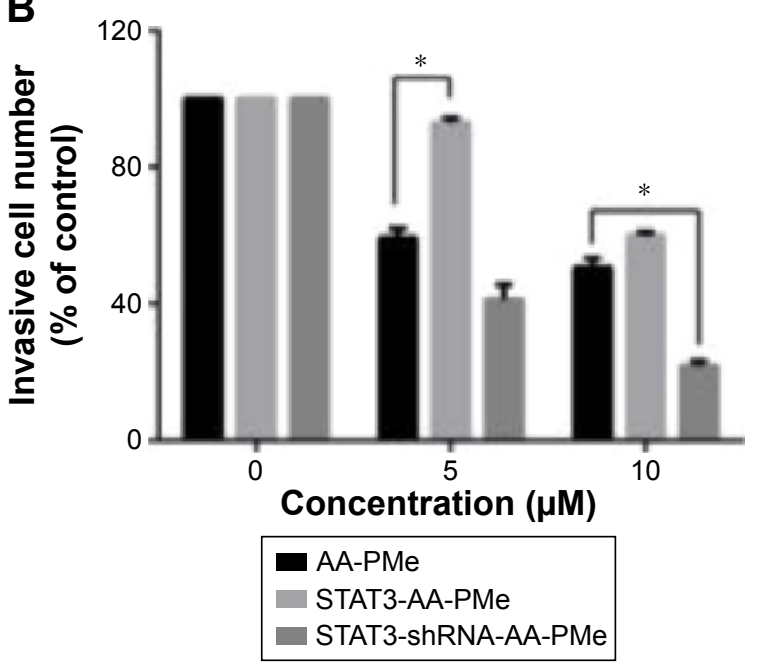

C

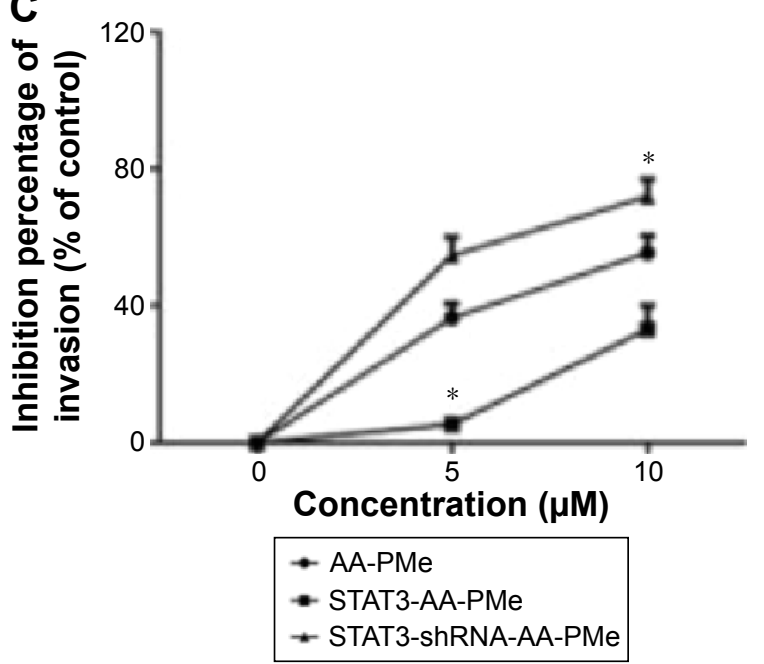

Figure 8 AA-PMe modulated mobility by inhibiting STAT3 in gastric cancer cells.

Notes: (A) Knockdown and overexpression SGC790I cells were STAT3-depleted or STAT3-overexpressed, treated with different concentrations of AA-PMe, and subjected to the invasion assay. (B) Invasive cell number rate by counting. (C) Invasive cell was decolored by $33 \%$ acetic acid and then measured at 570 nm with a microplate reader. Cell invasive ability was expressed by inhibition percentage of invasion as well. Significant differences are denoted by $* P<0.05$.

Abbreviations: AA-PMe, asiatic acid-N-(2 $\alpha, 3 \beta, 23$-acetoxyurs-I2-en-28-oyl)-L-proline methyl ester; STAT3, signal transducers and activators of transcription 3.

upregulation of Bax. In addition, constitutively active STAT3 was increased in highly invasive and metastatic melanoma cells, which directly contributed to the overexpression of MMP-2. On the other hand, blockage of STAT3 activation has been shown to inhibit MMP-2 expression in invasive and metastatic melanoma cells. ${ }^{30}$ This study aimed to explore whether AA-PMe exerted its anticancer effects through the abrogation of the STAT3 signaling pathway in gastric cancer cells.
Construction and transfection into SGC7901 cells of either a STAT3 shRNA or expression plasmid enabled us to either knockdown or overexpress STAT3. These transfected cells were then treated to different concentrations of AA-PMe to elucidate any changes in cell cycle, apoptosis, invasion, and/or STAT3-regulated proteins. It was found that this dietary factor suppressed constitutive STAT3 activation at both the protein and mRNA levels (Figure 2A-C). Results also showed that in human gastric cancer SGC7901 cells, 
the specific inhibition of JAK2 attenuated the activation of both JAK2 and STAT3 (Figure 3A). The knockdown or overexpression of STAT3 reversed survival rate (Figure 5), cell cycle arrest (Figure 6), apoptosis (Figure 7), and invasive phenotype (Figure 8) - all induced by AA-PMe. In addition to this, transfection of either a STAT3 mimic or inhibitor also changed the effect of STAT3 downstream gene products, which were affected by the application of AA-PMe (Figure 4).

The results presented a novel and significant finding in the demonstration of AA-PMe-induced downregulation of STAT3. This downregulation thereby inhibited JAK2STAT3 signaling and was the proposed mechanism for how AA-PMe inhibited gastric cancer cell growth. Although the mechanisms of JAK2-STAT3-mediated cancer apoptosis are well understood, the development of therapeutic drugs directly targeting this pathway remains unexplored. The present in vitro study showed that AA-PMe was able to inhibit STAT3, block JAK2-STAT3 signaling, and ultimately modulate cell survival and apoptotic downstream gene products of STAT3. These results suggest that blockade of STAT3 might be a crucial mechanism by which AA-PMe suppresses cell proliferation and induces apoptosis. This was supported by the finding that knockdown of STAT3 protected SGC7901 cells from apoptosis and weakened the effect of AA-PMe on gastric cancer cells. Contrastingly, overexpression of STAT3 seemed to amplify the influence of AA-PMe on gastric cancer cells.

Gastric cancer is the second most common cause of cancer-related death and its treatment options remain limited. $^{34}$ To this end, current treatment plans with systemic chemotherapy have led to disappointing outcomes, with both low response rates and high toxicity. Moreover, prolonged exposure to chemotherapies leads to the development of drug resistance and toxicity, shortening progression-free and overall survival times of patients. In summary, the low toxic AA-PMe, its capabilities to suppress STAT3 activation, downregulate the expression of cyclin D1, c-Myc, Bcl-2, MMP-9, and MMP-2, inhibit cell proliferation, induce cellular apoptosis, and restrain cell mobility, all warrant its further preclinical study preceding human trials.

\section{Disclosure}

The authors report no conflicts of interest in this work.

\section{References}

1. Huang S, Chen M, Shen Y, et al. Inhibition of activated Stat3 reverses drug resistance to chemotherapeutic agents in gastric cancer cells. Cancer Lett. 2012;315(2):198-205.
2. Ajani JA. Chemotherapy for gastric carcinoma: new and old options. Oncology (Williston Park). 1998;12(10 Suppl 7):44-47.

3. Darnell JE Jr. Transcription factors as targets for cancer therapy. Nat Rev Cancer. 2002;2(10):740-749.

4. Wei Z, Jiang X, Qiao H, et al. STAT3 interacts with Skp2/p27/p21 pathway to regulate the motility and invasion of gastric cancer cells. Cell Signal. 2013;25(4):931-938.

5. Bharti AC, Donato N, Aggarwal BB. Curcumin (diferuloylmethane) inhibits constitutive and IL-6-inducible STAT3 phosphorylation in human multiple myeloma cells. J Immunol. 2003;171(7): 3863-3871.

6. Buettner R, Mora LB, Jove R. Activated STAT signaling in human tumors provides novel molecular targets for therapeutic intervention. Clin Cancer Res. 2002;8(4):945-954.

7. Ihle JN. STATs: signal transducers and activators of transcription. Cell. 1996;84(3):331-334.

8. Ren Z, Schaefer TS. ErbB-2 activates Stat3 alpha in a Src- and JAK2dependent manner. J Biol Chem. 2002;277(41):38486-38493.

9. Catlett-Falcone R, Landowski TH, Oshiro MM, et al. Constitutive activation of Stat3 signaling confers resistance to apoptosis in human U266 myeloma cells. Immunity. 1999;10(1):105-115.

10. Gritsko T, Williams A, Turkson J, et al. Persistent activation of stat3 signaling induces survivin gene expression and confers resistance to apoptosis in human breast cancer cells. Clin Cancer Res. 2006;12(1): $11-19$.

11. Abdulghani J, Gu L, Dagvadorj A, et al. Stat3 promotes metastatic progression of prostate cancer. Am J Pathol. 2008;172(6):1717-1728.

12. Leeman-Neill RJ, Wheeler SE, Singh SV, et al. Guggulsterone enhances head and neck cancer therapies via inhibition of signal transducer and activator of transcription-3. Carcinogenesis. 2009;30(11): $1848-1856$.

13. Duan Z, Foster R, Bell DA, et al. Signal transducers and activators of transcription 3 pathway activation in drug-resistant ovarian cancer. Clin Cancer Res. 2006;12(17):5055-5063.

14. Bromberg JF, Wrzeszczynska MH, Devgan G, et al. Stat3 as an oncogene. Cell. 1999;98(3):295-303.

15. Yang C, Hornicek FJ, Wood KB, et al. Blockage of Stat3 with CDDO-Me inhibits tumor cell growth in chordoma. Spine (Phila Pa 1976). 2010; 35(18):1668-1675.

16. Aggarwal BB, Sethi G, Ahn KS, et al. Targeting signal-transducerand-activator-of-transcription-3 for prevention and therapy of cancer: modern target but ancient solution. Ann N Y Acad Sci. 2006;1091: 151-169.

17. Fletcher S, Turkson J, Gunning PT. Molecular approaches towards the inhibition of the signal transducer and activator of transcription 3 (Stat3) protein. ChemMedChem. 2008;3(8):1159-1168.

18. Yu H, Jove R. The STATs of cancer - new molecular targets come of age. Nat Rev Cancer. 2004;4(2):97-105.

19. Willett WC. Diet and health: what should we eat? Science. 1994; 264(5158):532-537.

20. Brinkhaus B, Lindner M, Schuppan D, Hahn EG. Chemical, pharmacological and clinical profile of the East Asian medical plant Centella asiatica. Phytomedicine. 2000;7(5):427-448.

21. Hsu YL, Kuo PL, Lin LT, Lin CC. Asiatic acid, a triterpene, induces apoptosis and cell cycle arrest through activation of extracellular signalregulated kinase and p38 mitogen-activated protein kinase pathways in human breast cancer cells. J Pharmacol Exp Ther. 2005;313(1): 333-344.

22. Tang XL, Yang XY, Jung HJ, et al. Asiatic acid induces colon cancer cell growth inhibition and apoptosis through mitochondrial death cascade. Biol Pharm Bull. 2009;32(8):1399-1405.

23. Cho CW, Choi DS, Cardone MH, Kim CW, Sinskey AJ, Rha C. Glioblastoma cell death induced by asiatic acid. Cell Biol Toxicol. 2006; 22(6):393-408.

24. Lee YS, Jin DQ, Kwon EJ, et al. Asiatic acid, a triterpene, induces apoptosis through intracellular $\mathrm{Ca} 2+$ release and enhanced expression of p53 in HepG2 human hepatoma cells. Cancer Lett. 2002;186(1):83-91. 
25. Park BC, Bosire KO, Lee ES, Lee YS, Kim JA. Asiatic acid induces apoptosis in SK-MEL-2 human melanoma cells. Cancer Lett. 2005; 218(1):81-90.

26. Jing Y, Wang G, Ge Y, Xu M, Gong Z. Synthesis, anti-tumor and antiangiogenic activity evaluations of asiatic acid amino acid derivatives. Molecules. 2015;20(4):7309-7324.

27. Pathak AK, Bhutani M, Nair AS, et al. Ursolic acid inhibits STAT3 activation pathway leading to suppression of proliferation and chemosensitization of human multiple myeloma cells. Mol Cancer Res. 2007; 5(9):943-955.

28. Yadav VR, Prasad S, Kannappan R, et al. Cyclodextrin-complexed curcumin exhibits anti-inflammatory and antiproliferative activities superior to those of curcumin through higher cellular uptake. Biochem Pharmacol. 2010;80(7):1021-1032.

29. Bowman T, Garcia R, Turkson J, Jove R. STATs in oncogenesis. Oncogene. 2000;19(21):2474-2488.
30. Xie TX, Wei D, Liu M, et al. Stat3 activation regulates the expression of matrix metalloproteinase-2 and tumor invasion and metastasis. Oncogene. 2004;23(20):3550-3560.

31. Jing Y, Wang G, Ge Y, Xu M, Tang S, Gong Z. AA-PMe, a novel asiatic acid derivative, induces apoptosis and suppresses proliferation, migration, and invasion of gastric cancer cells. Onco Targets Ther. 2016;17(9): 1605-1621.

32. Nielsen M, Kaestel CG, Eriksen KW, et al. Inhibition of constitutively activated Stat 3 correlates with altered Bcl-2/Bax expression and induction of apoptosis in mycosis fungoides tumor cells. Leukemia. 1999; 13(5):735-738.

33. Danial NN, Pernis A, Rothman PB. Jak-STAT signaling induced by the v-abl oncogene. Science. 1995;269(5232):1875-1877.

34. Siegel R, Naishadham D, Jemal A. Cancer statistics for Hispanics/ Latinos, 2012. CA Cancer J Clin. 2012;62(5):283-298.
OncoTargets and Therapy

\section{Publish your work in this journal}

OncoTargets and Therapy is an international, peer-reviewed, open access journal focusing on the pathological basis of all cancers, potential targets for therapy and treatment protocols employed to improve the management of cancer patients. The journal also focuses on the impact of management programs and new therapeutic agents and protocols on

\section{Dovepress}

patient perspectives such as quality of life, adherence and satisfaction. The manuscript management system is completely online and includes a very quick and fair peer-review system, which is all easy to use. Visit http://www.dovepress.com/testimonials.php to read real quotes from published authors. 